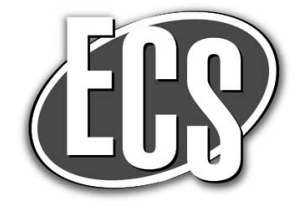

Jes Focus Issue on Electrolysis for Increased Renewable Energy Penetration

\title{
Hydrogen Production with a Simple and Scalable Membraneless Electrolyzer
}

\author{
Glen D. O'Neil,* Corey D. Christian, David E. Brown, and Daniel V. Esposito ${ }^{*, z}$
}

Department of Chemical Engineering, Columbia University, New York, New York 10027, USA

\begin{abstract}
Ion-conducting membranes are essential components in many electrochemical devices, but they often add substantial cost, limit performance, and are susceptible to degradation. This work investigates membraneless electrochemical flow cells for hydrogen production from water electrolysis that are based on angled mesh flow-through electrodes. These devices can be fabricated with as few as three parts (anode, cathode, and cell body), reflecting their simplicity and potential for low-cost manufacture. 3D printing was used to fabricate prototype electrolyzers that were demonstrated to be electrolyte agnostic, modular, and capable of operating with minimal product crossover. Prototype electrolyzers operating in acidic and alkaline solutions achieved electrolysis efficiencies of $61.9 \%$ and $72.5 \%$, respectively, (based on the higher heating value of $\mathrm{H}_{2}$ ) when operated at $100 \mathrm{~mA} \mathrm{~cm}^{-2}$. Product crossover was investigated using in situ electrochemical sensors, in situ imaging, and by gas chromatography (GC). GC analysis found that $2.8 \%$ of the $\mathrm{H}_{2}$ crossed over from the cathode to the anode stream under electrolysis at $100 \mathrm{~mA} \mathrm{~cm}^{-2}$ and fluid velocity of $26.5 \mathrm{~cm} \mathrm{~s}^{-1}$. Additionally, modularity was demonstrated with a three-cell stack, and high-speed video measurements tracking bubble evolution from electrode surfaces provide valuable insight for the further optimization of electrolyzer design and performance.

(C) The Author(s) 2016. Published by ECS. This is an open access article distributed under the terms of the Creative Commons Attribution Non-Commercial No Derivatives 4.0 License (CC BY-NC-ND, http://creativecommons.org/licenses/by-nc-nd/4.0/), which permits non-commercial reuse, distribution, and reproduction in any medium, provided the original work is not changed in any way and is properly cited. For permission for commercial reuse, please email: oa@electrochem.org. [DOI: 10.1149/2.0021611jes] All rights reserved.
\end{abstract}

Manuscript submitted February 18, 2016; revised manuscript received April 6, 2016. Published April 23, 2016. This was Paper 962 presented at the Phoenix, Arizona, Meeting of the Society, October 11-15, 2015. This paper is part of the JES Focus Issue on Electrolysis for Increased Renewable Energy Penetration.

Solar and wind energy have the potential to power the planet without the environmental impact of fossil fuels, but encounter significant challenges to widespread adoption due to their low capacity factors and inherent intermittency. ${ }^{1}$ In order to overcome this challenge, affordable grid-scale energy storage technology is needed that can make electricity generation from these technologies more widespread. ${ }^{2}$ One solution to this issue is to convert excess renewable electricity into stored chemical energy in the form of hydrogen gas $\left(\mathrm{H}_{2}\right),{ }^{3}$ which represents a promising candidate for grid scale energy storage and as a carbon-free replacement of fossil fuels in the transportation and industry sectors. ${ }^{4}$ Electrolyzers, which use electricity and water to produce hydrogen and oxygen, are well-established commercially available technologies, ${ }^{5}$ but the cost of producing $\mathrm{H}_{2}$ by water electrolysis is currently too expensive. ${ }^{6-8}$ Presently, much of the cost of producing $\mathrm{H}_{2}$ by water electrolysis comes from the price of electricity, ${ }^{6,8}$ but as the price of electricity from wind and solar continues to decrease and time-of-use pricing schemes become more prevalent, decreasing the cost of electrolyzer technology will be of great importance to making a renewable hydrogen future a reality.

The majority of electrolyzers are based on a design in which the cathode and anode are separated by an ion-conducting membrane or diaphragm. ${ }^{9}$ The two most common types of electrolyzers are alkaline and polymer electrolyte membrane (PEM) electrolyzers, which are able to electrolyze alkaline and ultra-pure water, respectively. These electrolyzers are mature technologies, and are capable of operating at very high current densities $\left(0.1-0.4 \mathrm{~A} \mathrm{~cm}^{-2}\right.$ for alkaline and $>1.6 \mathrm{~A}$ $\mathrm{cm}^{-2}$ for PEM), and producing high purity $\mathrm{H}_{2}$ (>99\% for alkaline, and $>99.999 \%$ for PEM) ${ }^{5}$ Within these devices, the membrane serves two key purposes, which are facilitating ion transport between the anode and cathode, and physically separating the product species produced at the anode and cathode to prevent crossover. ${ }^{10,11}$ Despite their importance to device operation, the membranes of these electrolyzers can be costly, prone to degradation or fouling, ${ }^{12-16}$ increase cell resistance, and entail the use of a membrane electrode assembly (MEA)-based design that requires at least 10 components. ${ }^{14,17-19}$ The high cost of

\footnotetext{
*Electrochemical Society Member
}

${ }^{\mathrm{z}}$ E-mail: de2300@columbia.edu electrolyzers arises from the high costs of individual components (e.g., membranes, bipolar plates, spacers, catalyst, etc.), as well as the cost of assembling the electrolyzer. In this work, we seek to substantially decrease both materials and assembly costs by exploring novel membraneless electrolyzer designs. In addition to eliminating the material costs of membranes and associated components, a membraneless electrolyzer can significantly relax design constraints associated with an MEA-based electrolyzer, opening up the possibility for a substantially simplified overall device that is amenable to low-cost, high volume assembly and manufacturing.

Membraneless co-laminar flow-cells based on flow-by band electrodes have been demonstrated for fuel cell ${ }^{20-24}$ and flow battery ${ }^{24-27}$ applications. These studies revealed the potential for efficient membraneless device operation without significant crossover of species between the anode and cathode, but face significant challenges to scale-up beyond microfluidic applications. ${ }^{23}$ More recently, Hashemi et al. reported a membraneless flow-by device that utilizes the SegréSilberberg effect within a laminar-flow microfluidic device in order to maintain separation of $\mathrm{H}_{2}$ and $\mathrm{O}_{2}{ }^{28}$ The authors observed as low as $0.4 \%$ product crossover (at $71.5 \mathrm{~mA} \mathrm{~cm}^{-2}$ ) and demonstrated current densities $>300 \mathrm{~mA} \mathrm{~cm}^{-2}$. While novel and exciting, this configuration was based on $70 \mu \mathrm{m}$ wide electrodes separated by $100 \mu \mathrm{m}$, and has not yet been shown to be scalable. In contrast to the aforementioned studies based on flow-by electrodes, membraneless electrochemical cells based on porous flow-through electrodes utilize fluid flow that is orthogonal to the electrode. Early work by Sioda explored the influence of fluid flow on the limiting currents and potential distributions of wire-based mesh flow-through electrodes, ${ }^{29-32}$ but these electrodes were never incorporated into a scalable device for water electrolysis. Recently, two different research groups have reported the successful use of mesh flow-through electrodes for water electrolysis with a built-in means of product separation. ${ }^{33,34}$ In both studies, two closelyspaced mesh electrodes are placed parallel to each other with fresh electrolyte pumped between them so that the divergent electrolyte flow causes the $\mathrm{O}_{2}$ and $\mathrm{H}_{2}$ products to be carried away down separate tubes. Gillespie et al., demonstrated that their concept is capable of operating at high current densities under high flow-rates and electrolyte concentrations $(30 \% \mathrm{KOH}) .{ }^{33}$ However, a potential disadvantage of this electrolyzer set-up is that it still contains many components, and 
(a)

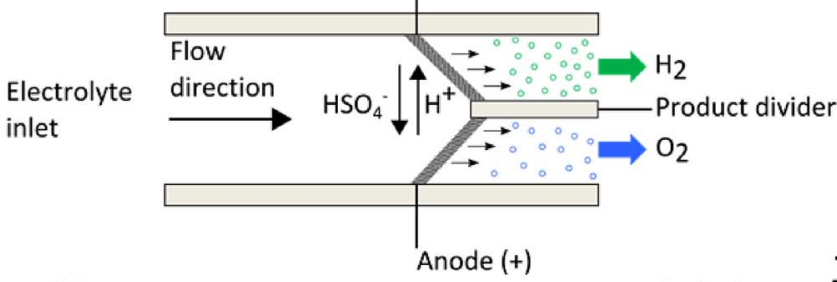

(b)

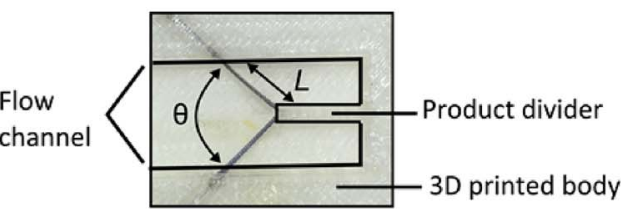

(c)

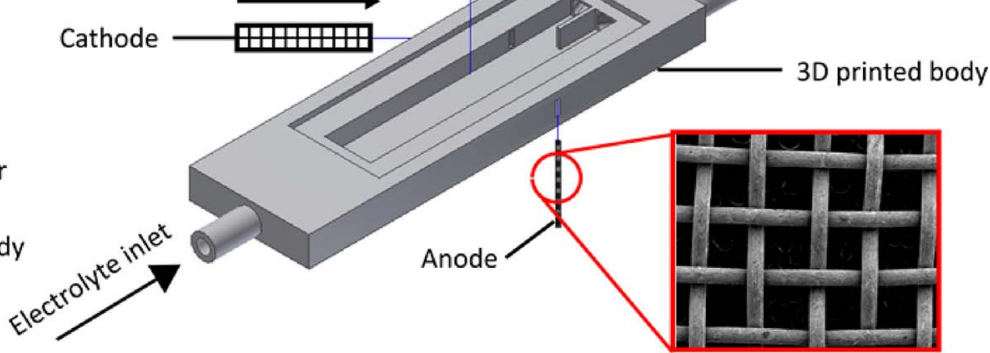

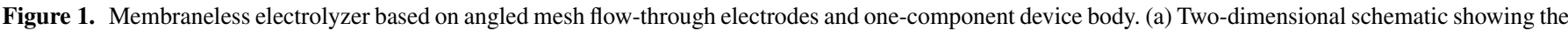

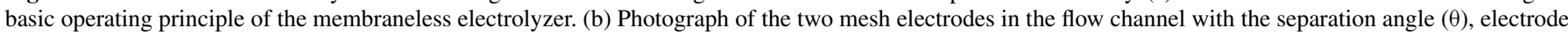

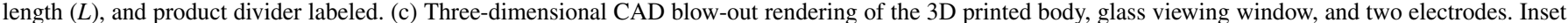
shows an SEM image of platinized titanium mesh electrode.

although modularity of the cells was demonstrated, scalability of individual cells based on circular mesh electrodes is likely to be limited by the annular flow configuration that was employed.

Herein, we present a simple membraneless electrolyzer design that may be fabricated by low-cost manufacturing techniques (e.g., injection molding) and has been demonstrated to produce hydrogen gas with low product crossover and relatively high electrolysis efficiency. The significant advance is the design of cells with angled flow-through electrodes that can be integrated into a 1- or 2-component device body (Fig. 1), greatly reducing the number of components that must be assembled. This electrolyzer cell design technically requires only three components (anode mesh, cathode mesh, and cell body), although a glass window (Fig. 1c) was placed on the top of prototypes used in this study in order to enable in situ imaging during operation. In this design, an aqueous electrolyte solution flows through two porous mesh electrodes, ${ }^{22,35}$ which are placed at an angle $(\theta)$ in close proximity to each other. Similar to the devices described by Gillespie and Hartvigsen, ${ }^{33,34}$ these electrolyzers do not require a membrane to achieve low product gas crossover because they employ flow-induced separation of product gases. Once detached from the electrodes, gaseous products are immediately swept down one of two effluent channels that are separated by a thin divider that is part of the cell body (Fig. 1b). The divider is distinguished from a membrane in that it is completely insulating - ionic current must instead flow through the aqueous electrolyte solution. Placing the flow-through electrodes at an angle relative to each other has advantages compared to parallel electrodes: fresh electrolyte constantly bathes the entire electrode, and the electrodes may be more seamlessly integrated into a single-component device body. Furthermore, unlike circular parallel flow-through electrodes with annular inlet flow, scalability of individual electrolysis cells comprised of angled flow-through electrodes may be easily achieved by increasing the height of the mesh electrodes.

\section{Experimental}

Materials._All solutions were prepared using $18.2 \mathrm{M} \Omega \mathrm{cm}$ water. Concentrated sulfuric acid (Certified ACS plus, Fischer Scientific), sodium sulfate (ACS Reagent grade, Sigma Aldrich), potassium tetrachloroplatinate (99.99\% trace metals basis, Sigma Aldrich), sodium chloride (ACS Reagent grade, Sigma Aldrich) and universal $\mathrm{pH}$ indicator ( $\mathrm{pH} 4-10$, Sigma Aldrich) were used as received without further modification. 3D printed electrolyzers were made from natural color poly(lactic acid) (PLA) or white acrylonitrile butadiene styrene (ABS) filaments (MakerBot Industries). Titanium ( 80 mesh; $130 \mu \mathrm{m}$ wire diameter) and nickel (100 gauze; $100 \mu \mathrm{m}$ wire diameter) meshes were purchased from Alfa-Aesar and were cut using Titanium scissors to an appropriate size.

Electrode fabrication.-Electrodeposition of Pt particles onto the Ti mesh electrodes was performed in a solution of $3 \mathrm{mM} \mathrm{K}_{2} \mathrm{PtCl}_{4}$ and $0.5 \mathrm{M} \mathrm{NaCl}(\mathrm{pH}=3.15)$ by performing cyclic voltammetry (CV) between 0.3 and $-0.7 \mathrm{~V}$ vs. $\mathrm{Ag} \mid \mathrm{AgCl}$ for 20 cycles (Fig. S1). Before electrodeposition, the $\mathrm{Ti}$ electrodes were pre-treated using double-step chronoamperometry in $0.5 \mathrm{M} \mathrm{H}_{2} \mathrm{SO}_{4}$, which improved the reproducibility of the electrodepositions. The first pulse at +2.5 $\mathrm{V}$ vs. $\mathrm{Ag} \mid \mathrm{AgCl}$ for three seconds seeks to remove carbonaceous impurities, and the second pulse at $-2.5 \mathrm{~V}$ vs. $\mathrm{Ag} \mid \mathrm{AgCl}$ removes the oxide from the Ti surface. This electrodeposition procedure produced quasi-spherical $\sim 300 \mathrm{~nm}$ platinum nanoparticles on the surface of the titanium (Fig. S2). Current densities are based on the 2D area of the mesh electrodes, which possessed electrochemically active surface areas (ECSA) of $\approx 5 \mathrm{~cm}^{2} \mathrm{Pt}$ per $\mathrm{cm}^{2}$ mesh based on analysis of the hydrogen underpotential deposition $\left(\mathrm{H}_{\text {upd }}\right)$ signal in $\mathrm{CV}$ curves. The $\mathrm{Ni} \mid \mathrm{NiOOH}$ electrocatalyst layer was prepared by performing $\mathrm{CV}$ using a $\mathrm{Ni}$ mesh electrode for 100 cycles between +0.2 and $+1.7 \mathrm{~V}$ vs. $\mathrm{Ag} \mid \mathrm{AgCl}$ in $1 \mathrm{M} \mathrm{KOH}$.

Electrolyzer fabrication.-The bodies of the electrolyzers were designed in AutoDesk Inventor Professional CAD software. The three dimensional CAD files are available free of charge at the website: http://echem.io/. The fluidic channel was $7.0 \mathrm{~cm}$ long and $1.3 \mathrm{~cm}$ wide and $0.5 \mathrm{~cm}$ high, with a 1.0 by $0.1 \mathrm{~cm}$ gas divider placed downstream of the electrodes (Fig. 1b). For most flow rates used in this study, the hydrodynamic entrance length is less than the device length, and thus the velocity profile should be fully developed before impinging upon the electrodes. The cross-section of each product channel was 0.5 by $0.6 \mathrm{~cm}$. The inlets and outlets were $4.0 \mathrm{~cm}$ ID. The channel height of $0.5 \mathrm{~cm}$ was chosen to closely match the inner diameter of the inlet/outlet tubing $(0.4 \mathrm{~cm})$ and thereby minimize mixing and eddying within the channels at the device entrance and exit regions. The channel width was chosen for a similar reason, with the 1.3 $\mathrm{cm}$ wide channel divided into two effluent channels with widths and heights that closely matched the diameter of tubing connected to the effluent outlets. All of the devices used herein were printed on a MakerBot replicator 2.0 3D printer (MakerBot Industries) using PLA 
(for acidic or neutral electrolytes) or ABS (for alkaline electrolytes) filament. Electrolyzer bodies were printed at high resolution, with a $0.1 \mathrm{~mm}$ line height and $15 \%$ infill.

Membraneless flow cells were assembled by positioning two mesh electrodes (Fig. 1c, inset) within a 3D printed flow cell and epoxying them in place (LockTite or JB Weld 5 minute epoxy), waiting overnight for the epoxy to completely set. In order to visualize the inner-workings of the membraneless devices, a transparent glass window was sealed to the front flow cell by epoxying the glass directly to the cell body.

Device characterization and performance.-3D printed devices were characterized by cyclic voltammetry $(\mathrm{CV})$ and electrochemical impedance spectroscopy. All electrochemical experiments were performed using a Biologic SP-300 or -200 bi-potentiostat/galvanostat. All solutions were pumped using a Cole Parmer Masterflex L/S peristaltic pump equipped with an Easy Load II pump head. The pulsedflow from the peristaltic pump was dampened using a home-built pressure dampening system. High-speed videos were acquired using an Edgertronic high-speed camera operating at 500 frames per second and resolution of $1280 \times 1024$. The high-speed videos were taken with the camera in a 'macro photography' set-up: light was focused onto the camera sensor through a Nikon AF NIKKOR $50 \mathrm{~mm}$ lens operated with a reversal ring.

Analysis of product gas composition.-GC measurements were performed using an Agilent gas chromatograph equipped with a thermal conductivity detector (TCD) using He as a carrier gas. The hydrogen and oxygen gases were each collected in inverted glass cylinders sealed with rubber septa, which were placed over the outlet tubing of the electrolyzer. Product crossover was calculated according to a previous report ${ }^{28}$ by measuring the amount of hydrogen in the oxygen terminal and dividing by the total amount of hydrogen measured. The measured percent crossover of $\mathrm{H}_{2}$ from the cathode to the anode channel is likely to exceed that of $\mathrm{O}_{2}$ from the anode to the cathode channel due to the lower solubility of $\mathrm{H}_{2}$ and higher molar rate of $\mathrm{H}_{2}$ production compared to $\mathrm{O}_{2}$.

\section{Results and Discussion}

As described above and illustrated in Figure 1, membraneless electrolyzers based on platinized Ti mesh flow-through electrodes were fabricated by $3 \mathrm{D}$ printing. For this study, a series of devices were fabricated with a constant flow channel width and varied angle $\left(\theta=30^{\circ}\right.$, $60^{\circ}, 90^{\circ}$, or $180^{\circ}$ ) between the two mesh electrodes in order to systematically study the influence of electrode angle and area on device performance. For all cells, the channel width was kept constant so as to maintain similar hydrodynamics and an identical device footprint. The exact dimensions of the electrodes for all devices are provided in Table I.

In order to evaluate the efficiency of an electrolyzer and understand the sources of its efficiency losses, it is useful to consider the relationship between the electrolysis current, $i$, and the voltage, $V$, that is applied between the anode and cathode. The applied voltage is equal to the sum of the thermodynamically required voltage to split water $\Delta E^{o}$, and the voltages required to overcome kinetic, Ohmic, and

\begin{tabular}{|c|c|c|}
\hline Angle / degrees & Electrode Length / cm & Cross sectional area $/ \mathrm{cm}^{2}$ \\
\hline 180 & 0.60 & 0.24 \\
\hline 90 & 0.85 & 0.34 \\
\hline 60 & 1.2 & 0.48 \\
\hline 30 & 2.3 & 0.93 \\
\hline
\end{tabular}

mass transport losses: ${ }^{36}$

$$
V=\Delta E_{H_{2} O}^{o}+\eta_{H E R}+\eta_{O E R}+i R_{s}+\eta_{m t}
$$

where $\eta_{H E R}$ and $\eta_{O E R}$ are the kinetic overpotentials for hydrogen and oxygen evolution reactions (Equations 2 and 3, respectively), $i R_{s}$ is the Ohmic voltage loss resulting from series resistances $\left(R_{\mathrm{s}}\right)$, and $\eta_{m t}$ is the mass transfer overpotential. $\Delta E_{\mathrm{H}_{2} \mathrm{O}}^{o}$ is equal to $1.23 \mathrm{~V}$ under standard conditions and is given by the difference in standard reduction potentials for the hydrogen evolution reaction (HER) and oxygen evolution reaction (OER):

$$
\begin{gathered}
2 H^{+}+2 e^{-} \leftrightarrow H_{2} \\
2 H_{2} \mathrm{O} \leftrightarrow 4 H^{+}+O_{2}+4 e^{-}
\end{gathered}
$$

In order to achieve maximum electrolysis efficiency, the kinetic, mass transfer, and Ohmic losses must be minimized. $\eta_{H E R}$ and $\eta_{O E R}$ can be minimized by selecting efficient catalysts and using electrodes with high surface area, while $i R_{s}$ may be reduced by optimizing the cell geometry and maximizing electrolyte conductivity. $\eta_{m t}$ can be minimized by using high reactant concentrations and employing forced convection of the electrolyte.

Electrode preparation and characterization.-Platinized titanium mesh electrocatalysts were employed as both the anode and cathode of the membraneless electrolyzers for all measurements conducted in the $0.5 \mathrm{M} \mathrm{H}_{2} \mathrm{SO}_{4}$ electrolyte. The catalytic activity and stability of the electrodes in $0.5 \mathrm{M} \mathrm{H}_{2} \mathrm{SO}_{4}$ were evaluated outside of the flow cell in a 3-electrode arrangement by performing linear sweep voltammetry (LSV) and cyclic voltammetry (CV), respectively. LSVs were performed at $10 \mathrm{mV} \mathrm{s}^{-1}$ in $0.5 \mathrm{M} \mathrm{H}_{2} \mathrm{SO}_{4}$ over potential regions where the hydrogen (HER) and oxygen evolution reactions (OER) occurred. Tafel analysis of the $i R_{S}$-corrected LSV curves gives the following exchange current densities $\left(j_{\mathrm{o}}\right)$ and Tafel slopes $(\beta): \beta_{\mathrm{HER}}=$ $38.8 \pm 2.2 \mathrm{mV}, j_{\mathrm{o}, \mathrm{HER}}=6.6 \times 10^{-4} \mathrm{~A} \mathrm{~cm}^{-2} ; \beta_{\mathrm{OER}}=133.2 \pm 9.0 \mathrm{mV}$, $j_{\mathrm{o}, \mathrm{OER}}=1.8 \times 10^{-7} \mathrm{~A} \mathrm{~cm}^{-2}$ (Fig. S3). The kinetic overpotential loss associated with HER in $0.5 \mathrm{M} \mathrm{H}_{2} \mathrm{SO}_{4}$ is relatively small, showing an overpotential loss of $190 \mathrm{mV}$ at $100 \mathrm{~mA} \mathrm{~cm}^{-2}$ that is consistent with previous reports. ${ }^{37}$ The kinetic overpotential loss associated with the OER is $840 \mathrm{mV}$ at $100 \mathrm{~mA} \mathrm{~cm}^{-2}$, reflecting the poor kinetics for OER on $\mathrm{Pt} \mid \mathrm{Ti}$ in acidic solutions and the fact that OER kinetic losses are commonly the largest source of efficiency loss in water electrolysis at low/moderate current densities. ${ }^{14,17}$ The stability of the platinized Ti mesh electrodes was evaluated by $\mathrm{CV}$ cycling performed at 100 $\mathrm{mV} \mathrm{s}^{-1}$ for 100 cycles between -0.5 and $2.25 \mathrm{~V} \mathrm{Ag} \mid \mathrm{AgCl}$ in a threeelectrode cell (Fig. S4). The electrocatalyst samples prepared by this method showed very little degradation in performance during $100 \mathrm{CV}$ cycles.

Device characterization and performance.-Besides kinetic overpotential losses, the other major source of efficiency loss in electrolyzers is Ohmic resistance, which is highly dependent on device geometry and is usually dominated by the resistivity of the electrolyte/solution. In the present study, the solution resistance is influenced by the angle between the two electrodes $(\theta)$, the length of the electrode $(\mathrm{L})$, and the electrolyte conductivity $\left(\sigma_{\mathrm{s}}=0.2 \mathrm{~S} \mathrm{~cm}^{-1}\right.$ for $\left.0.5 \mathrm{M} \mathrm{H}_{2} \mathrm{SO}_{4}\right){ }^{38}$ Fig. $2 \mathrm{a}$ shows a plot of the solution resistance versus electrode angle $\theta$, where the former was measured by electrochemical impedance spectroscopy. Also shown is the total resistance of $0.5 \mathrm{M} \mathrm{H}_{2} \mathrm{SO}_{4}$ in the limit of parallel electrodes $\left(\theta=0^{\circ}\right)$ with a spacing of $1 \mathrm{~mm}$. As expected, $R_{\mathrm{s}}$ increases linearly with increasing $\theta$, which primarily results from decreasing the electrode area. The $30^{\circ}$ device exhibited the lowest measured $R_{\mathrm{S}}$ of $\approx 2 \Omega$, and Figure 2 a shows that further decreasing the angle between the electrodes should result in lower values of $R_{\mathrm{S}}$.

Electrolyzer efficiencies were evaluated from cyclic voltammograms recorded in $0.5 \mathrm{M} \mathrm{H}_{2} \mathrm{SO}_{4}$ under flowing conditions $(13.2 \mathrm{~cm}$ $\mathrm{s}^{-1}$ ). Looking at the CVs in Fig. $2 \mathrm{~b}$, the absolute current at a given voltage is observed to increase with decreasing angle due to the correspondingly larger electrode area, highlighting that the electrode area 
(a)

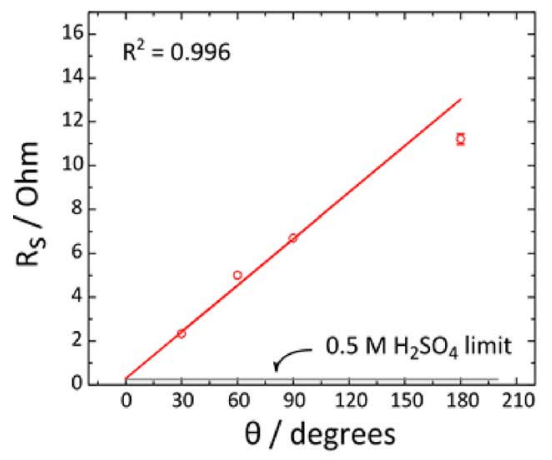

(b)

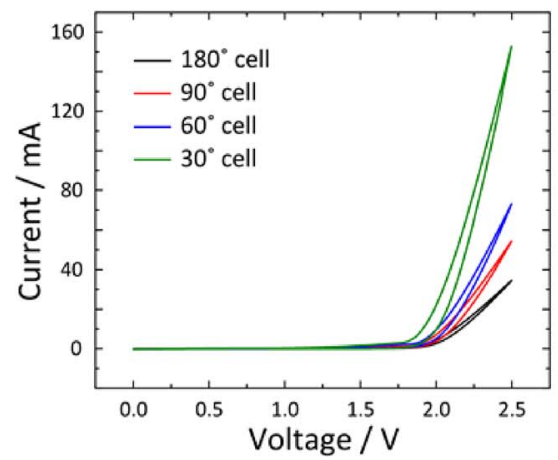

(c)

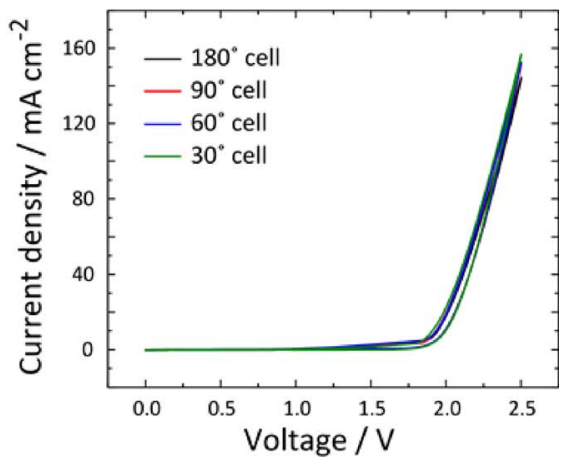

Figure 2. Electrochemical characterization of membraneless electrolysis cell in $0.5 \mathrm{M} \mathrm{H}_{2} \mathrm{SO}_{4}$ showing the influence of separation angle ( $\theta$ ) on solution resistance, current, and current density. (a) Solution resistance as a function of angle between electrodes measured using electrochemical impedance spectroscopy. The red line is a linear regression of the data. Conditions: $E_{\text {app }}=$ open circuit potential, $f=100 \mathrm{kHz}$, amplitude $=10 \mathrm{mV}$. Two-electrode cyclic voltammograms measured at $100 \mathrm{mV} \mathrm{s}^{-1}$ showing (b) current and (c) current density versus voltage for different device geometries with a fluid velocity of $13.2 \mathrm{~cm} \mathrm{~s}^{-1}$.

for this device footprint is maximized at smaller electrode angles. When the CV curves are instead plotted as current density versus voltage (Fig. 2c), they are observed to collapse on each other. Close inspection of these curves show that the current density marginally increases according to the following series: $180^{\circ}<60^{\circ}<90^{\circ}<30^{\circ}$. The efficiency for the $30^{\circ}$ device was calculated to be $61.9 \%$ at $100 \mathrm{~mA}$ $\mathrm{cm}^{-2}$, which compares well to other membraneless electrolyzers. ${ }^{28}$ Keeping consistent with previous electrolyzer literature, ${ }^{5}$ efficiency was calculated as the ratio of the cell voltage corresponding to the higher heating value $(\mathrm{HHV})$ of $\mathrm{H}_{2}\left(\Delta E^{\mathrm{o}}=1.48 \mathrm{~V}\right)$ and the applied voltage, $V$.

The presence of flowing electrolyte in these membraneless electrolyzers is of great importance for continuously delivering fresh electrolyte to the electrode surfaces, facilitating removal of product gases, and sweeping those gases into separate collection channels. The influence of flowing electrolyte on device performance is clearly seen in constant-voltage $i$-t curves, which are shown in Fig. 3 a for a $30^{\circ}$ cell under different flow rates. At $0 \mathrm{~cm} \mathrm{~s}^{-1}$ the $i$-t curve displays a 'sawtooth' pattern, which is caused by bubble growth on and detachment from the electrode surface. ${ }^{39}$ In the absence of flowing electrolyte (Fig. $3 b)$, gaseous bubbles build up on the electrode surfaces and decrease device efficiency by increasing cell resistance and blocking the electrocatalytic surfaces from fresh electrolyte. In contrast, operating the device under a flow rate of $6.6 \mathrm{~cm} \mathrm{~s}^{-1}$ results in a significant increase in current and a disappearance of the saw-tooth pattern, consistent with the visual observation that the generated bubbles are continu- (a)

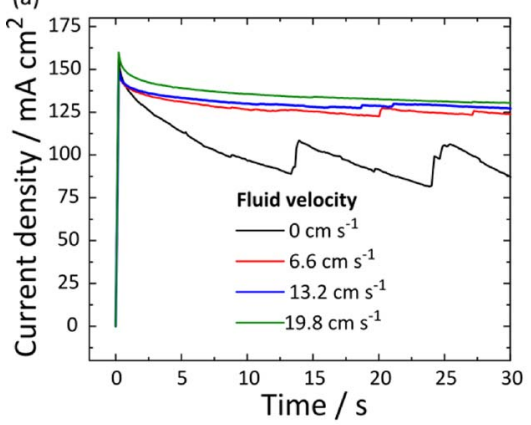

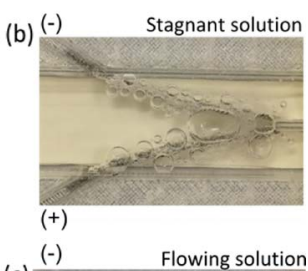

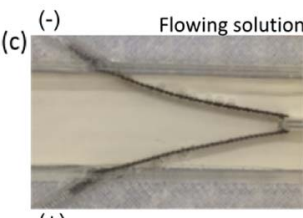

$(+)$
Figure 3. Effect of flowing electrolyte on the removal of product gas bubbles during electrolysis. (a) Two-electrode chronoamperometric $i$-t curve in $0.5 \mathrm{M}$ $\mathrm{H}_{2} \mathrm{SO}_{4}$ using different flow velocities at $2.5 \mathrm{~V}$. (b) Photograph showing the buildup of bubbles on the electrodes in stagnant solution during electrolysis at $2.5 \mathrm{~V}$. (c) Photograph taken during electrolysis in a flowing electrolyte with fluid velocity of $13.2 \mathrm{~cm} \mathrm{~s}^{-1}$ at $2.5 \mathrm{~V}$. ously removed from electrode surface (Fig. 3c). Increasing the fluid velocity further to $13.2 \mathrm{~cm} \mathrm{~s}^{-1}$ results in nominal improvement in the measured current density.

The ability of the membraneless electrolyzers to operate in different electrolytes was demonstrated by evaluating the performance of a $30^{\circ}$ device in $0.5 \mathrm{M} \mathrm{H}_{2} \mathrm{SO}_{4}(\mathrm{pH}=0.35), 1 \mathrm{M} \mathrm{Na}_{2} \mathrm{SO}_{4}(\mathrm{pH}=5.5)$, and $1 \mathrm{M} \mathrm{KOH}(\mathrm{pH}=13.7)$. A major advantage of an electrolyzer that can function in neutral and alkaline electrolytes is that there are a number of earth abundant, non-noble metal catalysts that can be employed without sacrificing efficiency or stability compared to their noble metal counterparts. ${ }^{40,41}$ An additional benefit of operating a membraneless device in alkaline or neutral $\mathrm{pH}$ is that the performance of ion-exchange membranes for non-acidic $\mathrm{pH}$ lags behind that of proton-exchange membranes such as Nafion. ${ }^{42}$ Fig. 4 shows $2-$ electrode $\mathrm{CV}$ curves for a $30^{\circ}$ device in the three different electrolytes. In the near-neutral $\mathrm{Na}_{2} \mathrm{SO}_{4}$ solution, the electrical efficiency is $49.7 \%$ at $50 \mathrm{~mA} \mathrm{~cm}{ }^{-2}$. Using the same device geometry and catalyst combination $(\mathrm{Ti} \mid \mathrm{Pt})$, but replacing the electrolyte with $0.5 \mathrm{M} \mathrm{H}_{2} \mathrm{SO}_{4}$, the device was able to achieve $67.3 \%$ efficiency at $50 \mathrm{~mA} \mathrm{~cm}^{-2}$. The significant difference between neutral and acidic electrolytes is observed because the Pt electrocatalyst is less active in $1 \mathrm{M} \mathrm{Na}_{2} \mathrm{SO}_{4}$ than in $0.5 \mathrm{M} \mathrm{H}_{2} \mathrm{SO}_{4}$, as reflected by the $\approx 0.5 \mathrm{~V}$ shift in the onset voltage for electrolysis current. $\mathrm{Na}_{2} \mathrm{SO}_{4}$ also has lower conductivity than $\mathrm{H}_{2} \mathrm{SO}_{4}$,

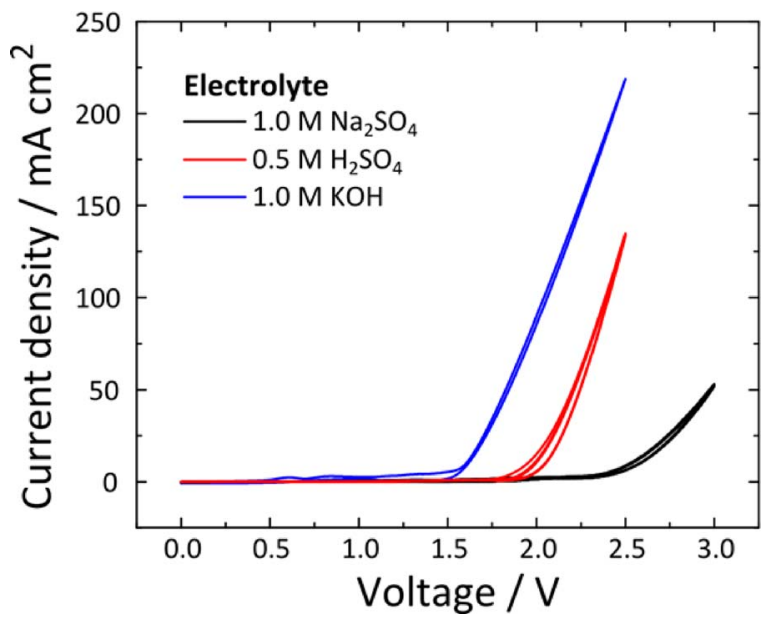

Figure 4. Performance of membraneless electrolyzers in different electrolytes. For $\mathrm{H}_{2} \mathrm{SO}_{4}$ and $\mathrm{Na}_{2} \mathrm{SO}_{4}$, both the cathode and anode were electrodeposited $\mathrm{Pt}$ on $\mathrm{Ti}$ mesh. For $\mathrm{KOH}$ the cathode was electrodeposited $\mathrm{Pt}$ on Ti mesh, and the anode was $\mathrm{Ni} \mid \mathrm{NiOOH}$. Scan rate $=100 \mathrm{mV} \mathrm{s}^{-1}$, and fluid velocity of $13.2 \mathrm{~cm} \mathrm{~s}^{-1}$. 
which results in a larger solution resistance of $4.6 \Omega$ as measured by EIS, and correspondingly a shallower slope in the CV curve. For electrolysis in the $1 \mathrm{M} \mathrm{KOH}$ solution, a $30^{\circ}$ device was fabricated using ABS because the PLA is not stable in strongly alkaline conditions. Additionally, a $\mathrm{Ni} \mid \mathrm{NiOOH}$ OER catalyst was prepared by cycling a Ni mesh electrode in $1 \mathrm{M} \mathrm{KOH} 100$ times between +0.2 and $+1.7 \mathrm{~V}$ vs. $\mathrm{Ag} \mid \mathrm{AgCl}$. This electrocatalyst was used as the anode in order to minimize kinetic overpotential losses. From the CV in Figure 4, the electrolyzer operated under alkaline conditions had an electrolysis efficiency of $81.3 \%$ at $50 \mathrm{~mA} \mathrm{~cm}^{-2}$, and $72.5 \%$ at $100 \mathrm{~mA} \mathrm{~cm}^{-2}$. This latter value was $\approx 15 \%$ higher than that recorded in $0.5 \mathrm{M} \mathrm{H}_{2} \mathrm{SO}_{4}$.

Product separation and collection.-In addition to being efficient and stable, a commercially viable membraneless electrolyzer must also be able to produce high purity $\mathrm{H}_{2}$, and collect a high percentage of $\mathrm{H}_{2}$ product from the catholyte stream. The purity of the product stream is of great importance for safe operation (the lower flammability limit for $\mathrm{H}_{2}$ in $\mathrm{O}_{2}$ is $\approx 4 \%$ ), ${ }^{34}$ and because many downstream applications require high purity $\mathrm{H}_{2}$. In membraneless devices, a major concern for low product purity is crossover of the product gases between the two electrodes during operation. In this study, crossover phenomena were analyzed in three different experiments. First, crossover was visualized colorimetrically by conducting electrolysis in the presence of a universal $\mathrm{pH}$ indicator $(\sim 6 \% \mathrm{v} / \mathrm{v})$ in a $1 \mathrm{M} \mathrm{NaCl}$ supporting electrolyte, an approach that has previously been used to observe the $\mathrm{pH}$ induced changes in bipolar electrochemical cells. ${ }^{43} \mathrm{~A}$ pH-neutral electrolyte was chosen because of its poor buffering capabilities, meaning that local $\mathrm{pH}$ changes caused by the OER and HER reactions result in color change by the $\mathrm{pH}$ indicator dye. ${ }^{42}$ In the absence of electrolysis, the $\mathrm{pH}$ indicator dye exhibits a characteristic pink color in the weakly acidic supporting electrolyte (Fig. 5a). Performing electrolysis increases the local $\mathrm{pH}$ at the cathode mesh due to the consumption of protons, causing the $\mathrm{pH}$-sensitive dye to turn purple (Figures $5 \mathrm{~b}, 5 \mathrm{c}$ ). In the presence of flowing electrolyte (fluid velocity $\approx 15.4 \mathrm{~cm} \mathrm{~s}^{-1}$ ), the purple-stained effluent produced at the cathode flows exclusively down the cathode channel of the device, with no indication of cathode effluent crossing over into the anode channel. By contrast, the purplecolored product plume produced in the quiescent electrolyte (Fig. 5c) quickly expands into the area between the two mesh electrodes. This result highlights the necessity of having a flowing electrolyte to achieve efficient separation of the anode and cathode product species.

$\mathrm{H}_{2}$ crossover from the cathode to the anode channel was also measured in situ using an electrochemical sensor, ${ }^{44-47}$ which was integrated directly into the electrolyzer at a location $\approx 5 \mathrm{~mm}$ downstream of the anode (Fig. 6a), similar to previous generation-collection experiments in the literature. ${ }^{48}$ The electrochemical sensor was a platinized titanium mesh electrode spanning the entire effluent flow channel and operated amperometrically at $+0.8 \mathrm{~V}$ vs. $\mathrm{Ag} \mid \mathrm{AgCl}$, a potential at which it is selective to only dissolved $\mathrm{H}_{2}$ without interference from dissolved $\mathrm{O}_{2}$ (see Figs. S5 and S6 in SI section S2 for details and control experiments). For these experiments, the reference electrode was placed in the inlet tubing of the flow-cell. Under the applied potential of $+0.8 \mathrm{~V}$ vs. $\mathrm{Ag} \mid \mathrm{AgCl}$, the sensor oxidizes dissolved $\mathrm{H}_{2}$ molecules that reach its surface, resulting in oxidation current (the sensor signal) that is proportional to the concentration of dissolved $\mathrm{H}_{2}$ at the surface of the sensor. Figures $6 \mathrm{~b}-6 \mathrm{e}$ show the sensor current measured in a four electrode arrangement during electrolysis of $0.5 \mathrm{M} \mathrm{H}_{2} \mathrm{SO}_{4}$ at varying electrolyte flow rates. For all experiments, the applied potential of the hydrogen-evolving cathode was set at $-0.3 \mathrm{~V}$ vs. $\mathrm{Ag} \mid \mathrm{AgCl}$, resulting in current densities of $\approx 20 \mathrm{~mA} \mathrm{~cm}^{-2}$ at the anode and cathode mesh electrodes. At this current density, gas bubbles were seen evolving from the cathode and anode. Fig. $6 \mathrm{~b}$ contains a plot of the sensor current in a quiescent electrolyte during electrolysis (red trace) and before electrolysis (blue trace). The blue trace shows very low levels of noise compared to the red trace, for which spikes in oxidation current are observed due to hydrogen diffusing across the divider to the sensor electrode. As the flow velocity increases from 2.6 to $13.2 \mathrm{~cm} \mathrm{~s}^{-1}$ (Figs. 6c-6e), the sensor noise and average sensor signal (red traces) decrease, while the background signal measured
$(-)$

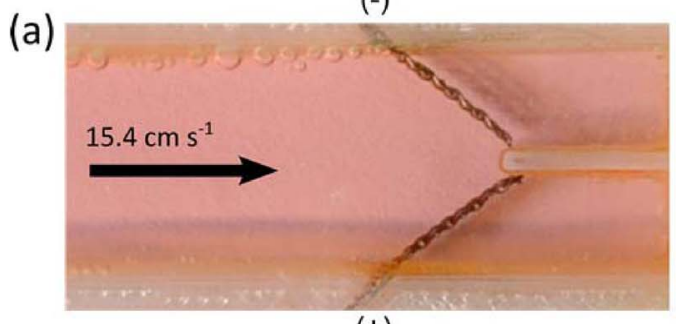

$(+)$

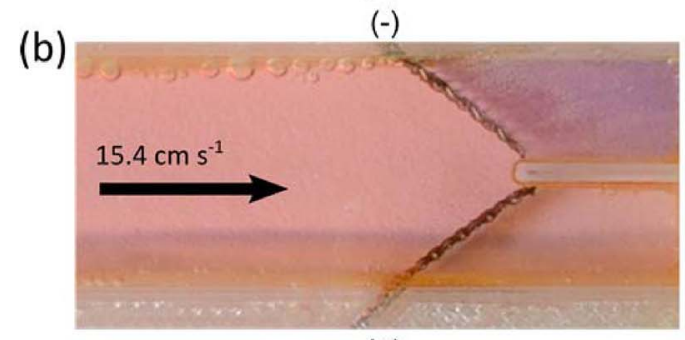

$(+)$

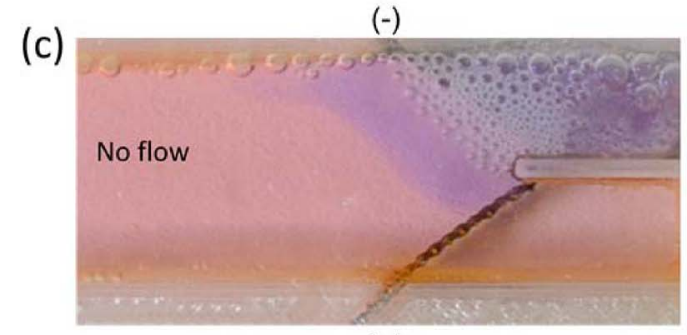

$(+)$

Figure 5. Imaging fluid dynamics of membraneless electrolyzers in the presence of a color-changing, $\mathrm{pH}$ sensitive dye. Images were taken (a) without electrolysis and under flowing electrolyte, (b) during electrolysis at $20 \mathrm{~mA}$ $\mathrm{cm}^{-2}$ with flowing electrolyte, and (c) during electrolysis at $20 \mathrm{~mA} \mathrm{~cm}^{-2}$ in a stagnant electrolyte. The fluid velocity was $15.4 \mathrm{~cm} \mathrm{~s}^{-1}$ in (a) and (b), and the electrolyte was comprised of $1 \mathrm{M} \mathrm{NaCl} / 6 \%$ universal $\mathrm{pH}$ indicator for all experiments. Note: discoloration on the anode side of the flow channel is a shadow, and bubbles visible along the upstream channel walls are air bubbles present at the start of the experiment.

in the absence of electrolysis is nearly unaffected. Fig. $6 f$ shows the average sensor signal collected over five fluid velocities from 0-19.8 $\mathrm{cm} \mathrm{s}^{-1}$ (flow rates $=0-12.9 \mathrm{~mL} \mathrm{~s}^{-1}$ ), indicating an exponential decay of the average sensor signal due to oxidation of $\mathrm{H}_{2}$ that had crossed over from the opposite channel. The average HOR sensor signal in the absence and presence of electrolysis is found to be statistically identical for fluid velocities above $6.6 \mathrm{~cm} \mathrm{~s}^{-1}$. The sharp decrease in sensor signal is thus consistent with a sharp decrease in $\mathrm{H}_{2}$ crossing over from the cathode to the anode compartment in the presence of flowing electrolyte. It should be noted that a decrease in HOR sensor signal is also expected to occur due to dilution of the crossed-over $\mathrm{H}_{2}$ at higher fluid flow rates. Further investigations are underway to deconvolute the two effects, but the measurements of Figure $6 \mathrm{f} \mathrm{high-}$ light the opportunity for inline, real-time monitoring of electrolyzer product purity using electrochemical sensors.

In order to confirm the validity of the in situ measurements, product crossover was further investigated by using GC to analyze the composition of the gas bubbles collected downstream of the electrolyzer in the anode and cathode effluent streams (Section S3 in the supporting information for details). In these experiments, electrolysis was conducted with the $30^{\circ}$ cell for 60 minutes at $100 \mathrm{~mA} \mathrm{~cm}^{-2}$ and a fluid velocity of $26.5 \mathrm{~cm} \mathrm{~s}^{-1}$. The product gasses were collected using a 'beehive stack' configuration as shown in Fig. 7a. Gaseous product from the cathode and anode collection tubes was sampled with a gastight syringe and immediately injected into the GC instrument. As detailed in the SI, analysis of GC data indicate that $97.2 \%$ of the 
(a)

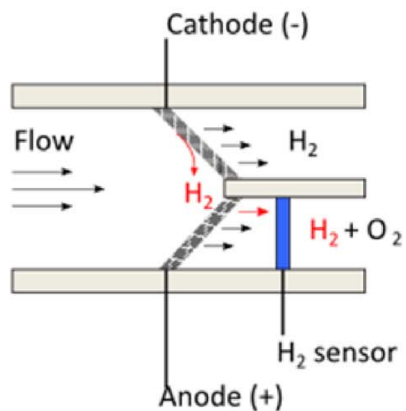

(d)

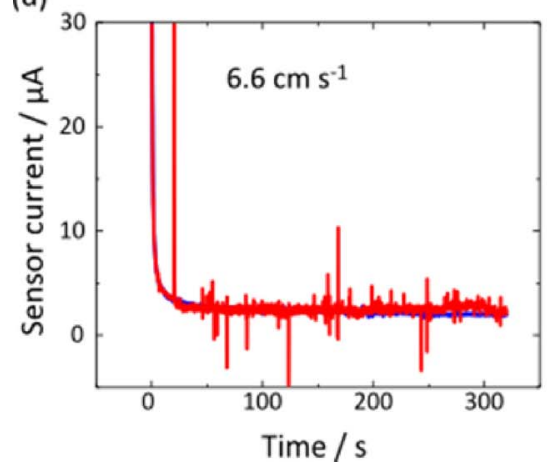

(b)

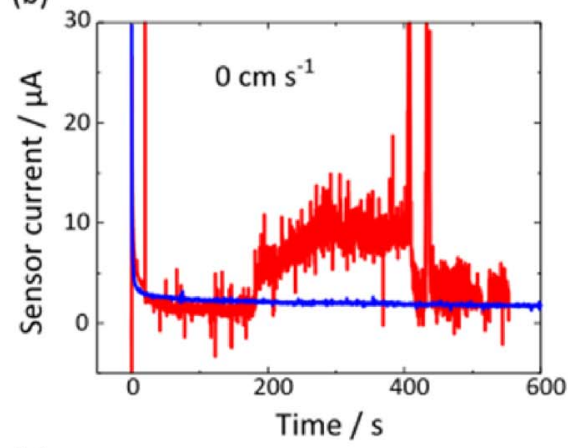

(e)

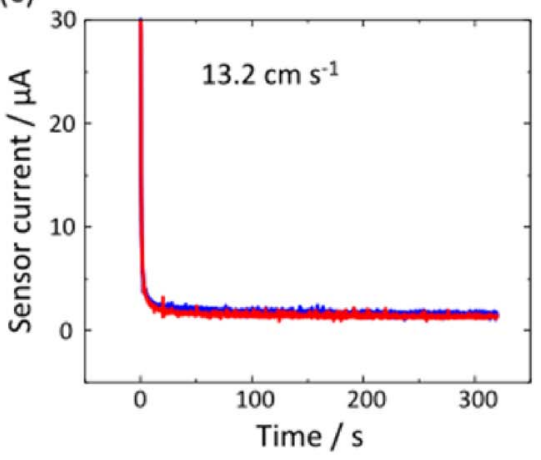

(c)

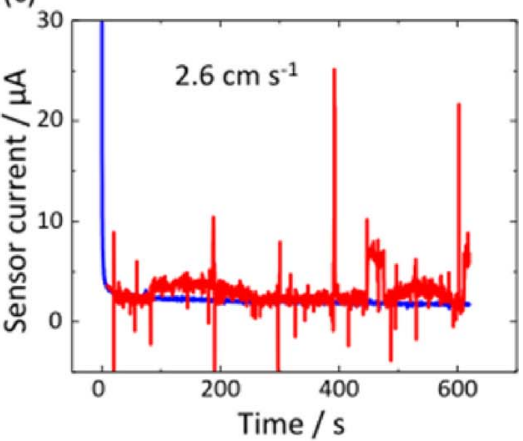

(f)

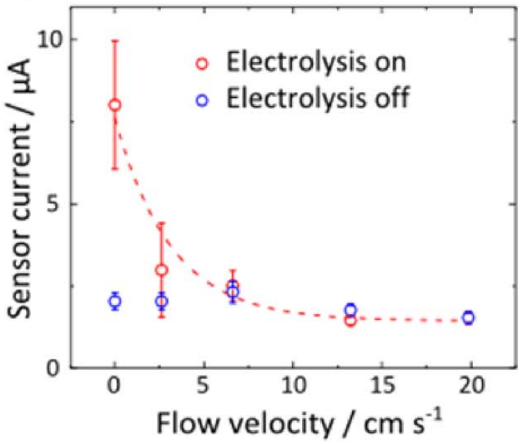

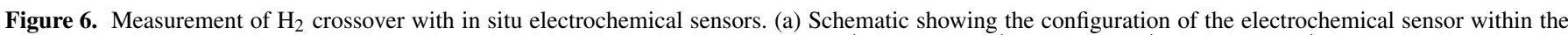

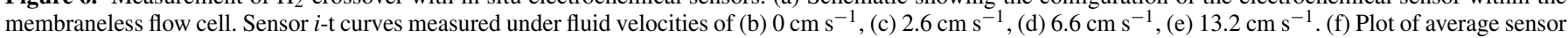

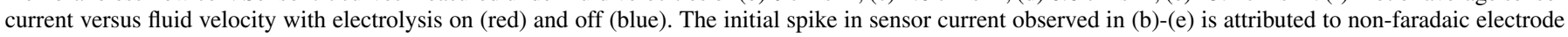
processes and is not used in computation of the averages in part (f).

gaseous $\mathrm{H}_{2}$ product was collected in the cathode terminal, with the remainder in the anode terminal. The value $(100-97.2 \%)=2.8 \%$ should serve as an upper estimate of the percentage of $\mathrm{H}_{2}$ that crosses over to the anode channel, since the experiment was conducted with a recirculating electrolyte stream in which small $\mathrm{H}_{2}$ bubbles that are not captured in the $\mathrm{H}_{2}$ collection tube have a $50 \%$ chance of ending up in the anode collection channel on subsequent passes. Additionally, the $30^{\circ}$ cell used for this measurement is expected to be the most susceptible to crossover of the devices investigated due to the acute angle between electrodes. With further modifications to operating conditions, device geometry, and gas collection apparatus, product purity should continue to improve to the levels achieved with membraneless electrolyzers by other researchers. ${ }^{28,33}$ No other species besides $\mathrm{H}_{2}$, $\mathrm{O}_{2}, \mathrm{~N}_{2}$, and $\mathrm{H}_{2} \mathrm{O}$ were observed in $\mathrm{GC}$ measurements.

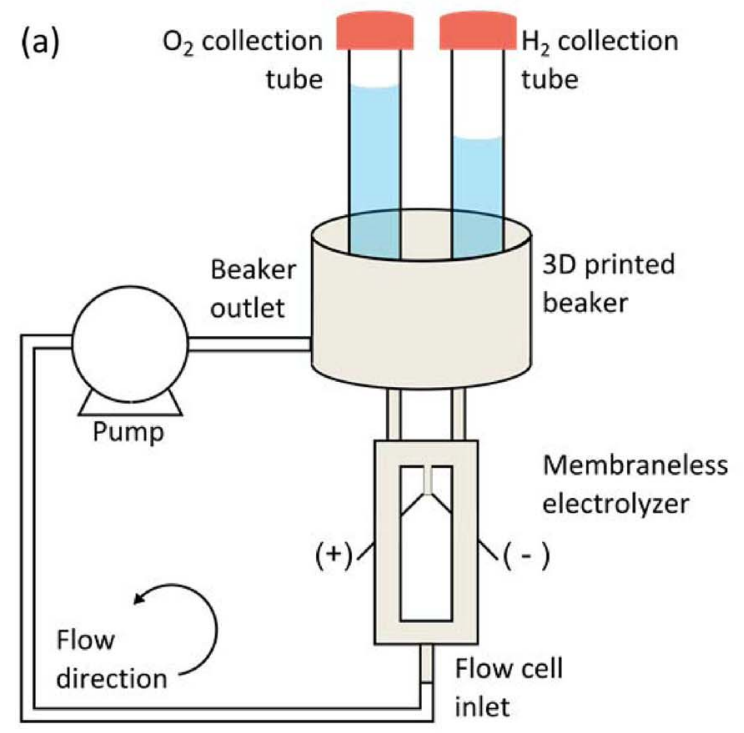

(b)

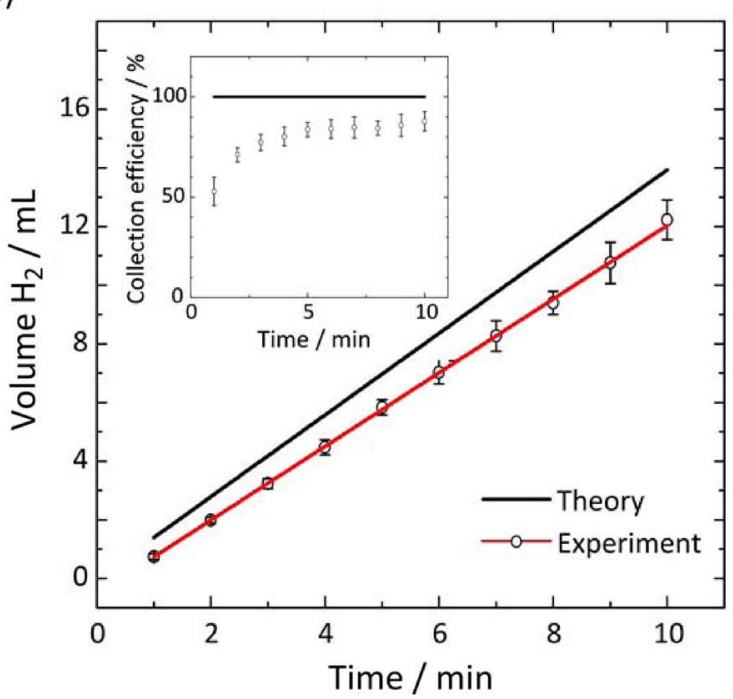

Figure 7. Measuring $\mathrm{H}_{2}$ collection efficiency. (a) Schematic showing a simplified set-up for measuring collection efficiency. (b) Hydrogen production rate as a function of time in the $30^{\circ}$ device. Inset: collection efficiency as a function of time. Experiments were performed at $6.6 \mathrm{~cm} \mathrm{~s}^{-1}$ with an applied current of $215 \mathrm{~mA}$ $\mathrm{cm}^{-2}$ in $0.5 \mathrm{M} \mathrm{H}_{2} \mathrm{SO}_{4}$. The cell was operated vertically as shown in Figure 7a. 
Another important performance metric for operation of a flowbased electrolyzer is the product gas collection efficiency, defined here as the percentage of generated $\mathrm{H}_{2}$ that is collected in a downstream reservoir. The collection efficiency will be adversely affected by product crossover between the anode and cathode, as well as dissolution of product gas in the aqueous phase. This latter loss mechanism is particularly important for operation of a flow cell device in which unsaturated electrolyte is continuously delivered to the electrode surface, but can be minimized by operating at high current densities and avoiding unnecessarily high flow rates. In this work, the collection efficiency was determined by volumetrically measuring the amount of $\mathrm{H}_{2}$ and $\mathrm{O}_{2}$ product gases collected downstream of the electrolyzer using inverted glass collection tubes connected to a 'beehive stack' apparatus (Fig. 7a). ${ }^{28}$ Fig. 7b shows a plot of gas volume collected as a function of time (open symbols) along with the theoretical amount of $\mathrm{H}_{2}$ which should be produced according to Faraday's law based on the applied current $\left(200 \mathrm{~mA}, 215 \mathrm{~mA} \mathrm{~cm}^{-2}\right)$ and time of electrolysis ( 1 min intervals). The rate of $\mathrm{H}_{2}$ collection was $1.26 \pm 0.01 \mathrm{~mL} \mathrm{~min}^{-1}$, equating to a collection efficiency of $\approx 90 \%$ when compared to that

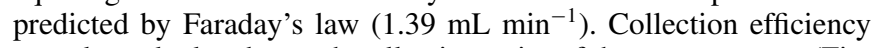
was also calculated at each collection point of the measurement (Fig. $4 \mathrm{~b})$, showing that the collection efficiency is initially low $(\approx 50 \%$ after 1 minute), but increases to a constant value of $\approx 90 \%$ after four minutes. This initial transient is primarily caused by the residence time associated with transport of the gas bubbles to the collection cylinder at the beginning of the experiment. Recorded collection efficiencies of $<100 \%$ are to be expected due to some dissolution of $\mathrm{H}_{2}$ in the aqueous electrolyte and the presence of gas bubbles on sidewalls of the tubing that connects the electrolyzer to the gas collection cylinder.

Device modularity and scalability.-The modularity of the electrolyzer design was evaluated by combining three cells in parallel (Fig. 8a) and measuring their performance. In these experiments, fluid manifolds were used to split the feed stream of the electrolyte and merge the product streams. Fig. $8 \mathrm{~b}$ shows the results of chronoamperometry experiments in which $2.2 \mathrm{~V}$ of potential was applied to the electrodes in the stack. When testing an individual cell in the stack (contacting one electrode pair while the other cells remain open), the values of the recorded current are similar for all cells $( \pm 15 \%)$. The variation in current between each cell can likely be attributed to small differences in the fluid velocity between each cell. The recorded current increases as a sum of the individual cells when the electrodes are connected in parallel. When the top $(i=32 \mathrm{~mA})$ and middle cells $(i=40 \mathrm{~mA})$ are connected, their additive current is $71 \mathrm{~mA}$. When the bottom electrode $(i=35 \mathrm{~mA})$ is added, the currents add to $107 \mathrm{~mA}$ as predicted. These experiments confirm that the devices can be scaled in a modular way, analogous to the addition of cells in a conventional PEM electrolysis stack.

Besides connecting multiple electrolyzer cells in parallel, another means of scaling up $\mathrm{H}_{2}$ production is to increase the size of the elec- (a)

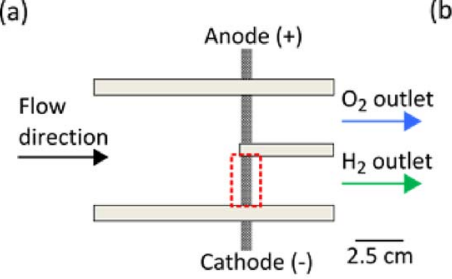

(c)

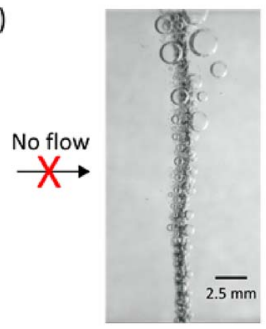

(b)

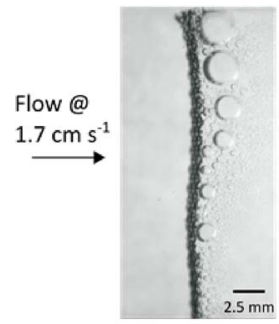

(d)

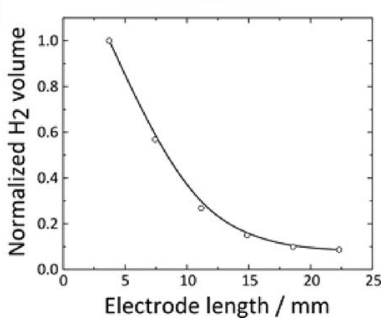

Figure 9. High speed video analysis of non-uniform current densities along the length of a mesh electrode. (a) Schematic of $5.1 \mathrm{~cm}$ wide membraneless flow cell. The red dashed box shows the area used for high-speed video imaging. Still-images from HSV analysis showing bubble formation along the $2.5 \mathrm{~cm}$ electrode under (b) flowing and (c) quiescent conditions. (d) Plot of normalized bubble volume as a function of electrode length. Note the line in (d) is not a fit of experimental data, but is shown as a guide to the eye. Electrolysis was performed at $50 \mathrm{~mA}$ in $0.5 \mathrm{M} \mathrm{H}_{2} \mathrm{SO}_{4}$.

trodes used within a single cell. A major advantage of the angled flow-through electrode design used in this work is that the electrode height can be scaled indefinitely without adversely affecting device performance. The electrode area can also be made larger by increasing the electrode length (L), but this increase in electrode area is achieved at the expense of increasing the average separation distance between the anode and cathode meshes. The larger separation distance associated with longer electrodes translates into larger solution $i R_{\mathrm{S}}$ losses during operation, and thus a lower electrolysis efficiency at a given applied potential. However, the solution $i R_{\mathrm{S}}$ losses are not uniform along the entire length of the angled electrodes, which results in nonuniform distribution of current flow between the anode and cathode.

In order to better understand the limits of scaling these membraneless devices and quantify the non-uniform current flow between angled electrodes, high speed video (HSV) ${ }^{49-51}$ was employed to study a membraneless electrolyzer having an electrode angle of $180^{\circ}$ and a channel width of $5.1 \mathrm{~cm}$ (Fig. 9a). This geometry was chosen to amplify the non-uniform current distribution along the length of the electrode for the purposes of imaging. Figure $9 \mathrm{~b}$ contains a still frame from a high-speed video that was taken of bubble evolution from a mesh cathode during electrolysis at $50 \mathrm{~mA}$ total applied current and a fluid velocity of $6.6 \mathrm{~cm} \mathrm{~s}^{-1}$. In these experiments, the hydrogen bubbles can be used to visually approximate the current distribution across
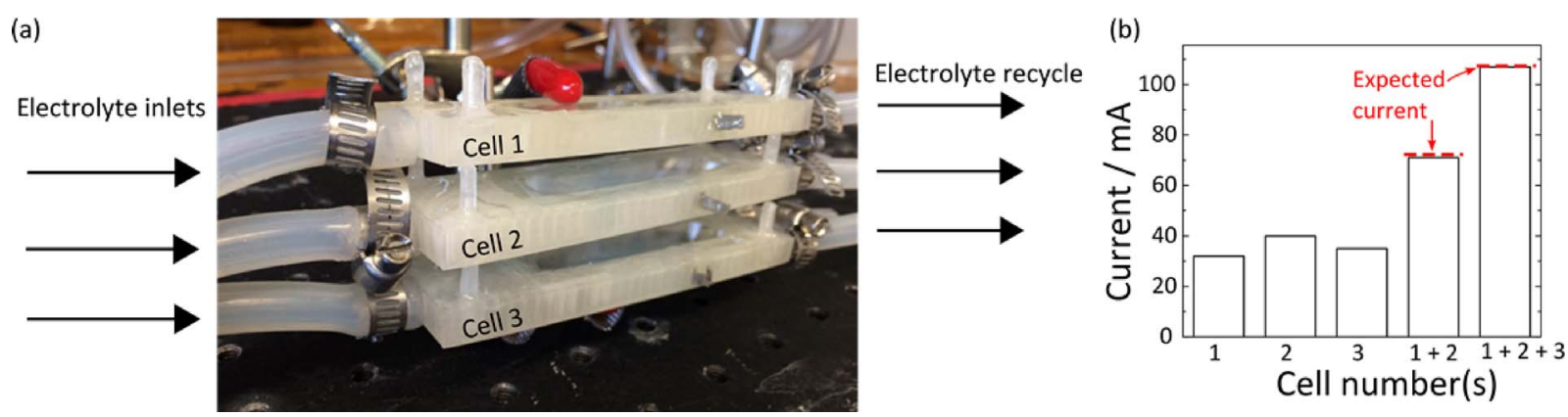

Figure 8. Demonstration of the modularity of the 3D printed membraneless water-splitting devices. (a) Photograph of 3 membraneless $45^{\circ}$ cells connected in parallel. (b) Total electrolysis current measured for individual cells and combinations of cells during operation at an applied voltage of $2.2 \mathrm{~V}$ in $0.5 \mathrm{M} \mathrm{H}_{2} \mathrm{SO}_{4}$ and under a fluid velocity of $4.4 \mathrm{~cm} \mathrm{~s}^{-1}$. The dashed red line shows the expected current for combinations of cells based on the current measured for each cell individually. 
the electrode surface, since the volume of the evolved $\mathrm{H}_{2}$ bubbles is proportional to the local current. Figure $9 \mathrm{~b}$ shows significant variation in the amount of gas produced along the length of the electrode, with a notable decrease in average bubble size in going from the top to the bottom of the electrode. This observation is consistent with expectations of lower current density at the bottom of the cathode due to the longer distance for ion transport between the cathode and anode. Fig. $9 \mathrm{c}$ shows the same device operating under quiescent conditions, for which bubbles are evolved symmetrically on both sides of the mesh electrode in the absence of fluid flow. As a semi-quantitative measure of the local variation in current density, the bubble volume was calculated as a function of electrode length (segmented into 6 sections) and plotted in Figure 9d. It is clear from Fig. 9 that when the electrodes and end-to-end spacing are large, there is a significant variation in local current density along the length of the electrode. The uneven current distribution can have a significant impact on both electrolysis efficiency and long-term stability caused by uneven electrode aging. This analysis highlights the opportunity for using high speed video to analyze local current density distributions in liquid-phase electrolysis. Efforts to combine in situ high speed video analysis with finite element modelling as a platform for guiding the design of more efficient membraneless electrolyzers are currently underway.

\section{Conclusions}

This work has investigated 3D printed membraneless electrolyzers based on angled mesh flow-through electrodes integrated into a simple device geometry. Thanks to flow-induced product separation and enhanced mass transfer, these electrolyzers can operate efficiently without a membrane. In alkaline electrolyte, an electrolysis efficiency of $72.5 \%$ (based on the HHV of $\mathrm{H}_{2}$ ) was measured at a current density of $100 \mathrm{~mA} \mathrm{~cm}{ }^{-2}$. Product gas crossover was investigated by in situ imaging, integrated electrochemical sensors, and GC analysis of product gases collected downstream from the electrolyzer. GC analysis found that $2.8 \%$ of the collected $\mathrm{H}_{2}$ gas crossed over from the cathode to the anode collection stream. In separate experiments, $\approx 90 \%$ of product gas was collected in a downstream collection apparatus, and a 3-cell stack was employed to demonstrate the modularity of the design. Improvements in all performance metrics are expected with further optimization of cell geometries and operating conditions. Most importantly, the simple design furthermore enables easy fabrication and assembly, providing an opportunity to significantly reduce the capital cost of $\mathrm{H}_{2}$ production from water electrolysis.

\section{Acknowledgment}

The authors acknowledge L. Taub and J. Murphey for their work with early device prototypes, C. Hawxhurst and J.G. Chen for assistance with gas chromatography measurements, A. Shiloh for assistance with ABS printing, J. Davis for helpful discussions, J. Qi and N. Labrador for SEM images, and Columbia University for start-up funding.

\section{References}

1. N. S. Lewis and D. G. Nocera, Proc. Natl. Acad. Sci. USA, 103, 15729 (2006).

2. H. Safaei and D. W. Keith, Energy Environ. Sci., 8, 3406 (2015).
3. J. R. McKone, N. S. Lewis, and H. B. Gray, Chem. Mater, 26, 407 (2014).

4. M. A. Pellow, C. J. M. Emmott, C. J. Barnhart, and S. Benson, Energy Environ. Sci., 8, 1938 (2015).

5. K. Harrison and J. I. Levene, in Solar Hydrogen Generation: Toward a Renewable Energy Future, K. Rajeshwar, R. McConnell, and S. Licht, Editors, p. 41, Springer, New York (2008).

6. F. Mueller-Langer, E. Tzimas, M. Kaltschmitt, and S. Peteves, Int. J. Hydrogen Energy, 32, 3797 (2007)

7. T. Abbasi and S. A. Abbasi, Renew. Sustain. Energy Rev., 15, 3034 (2011).

8. S. E. Hosseini and M. A. Wahid, Renew. Sustain. Energy Rev., 57, 850 (2016).

9. M. Carmo, D. L. Fritz, J. Mergel, and D. Stolten, Int. J. Hydrogen Energy, 38, 4901 (2013).

10. A. Berger, R. A. Segalman, and J. Newman, Energy Environ. Sci., 7, 1468 (2014).

11. D. M. F. Santos, C. A. C. Sequeira, and J. L. Figueiredo, Quim. Nov., 36, 1176 (2013).

12. A. Sadeghi Alavijeh, R. M. H. Khorasany, A. Habisch, G. G. Wang, and E. Kjeang, J. Power Sources, 285, 16 (2015).

13. R. M. H. Khorasany, A. Sadeghi Alavijeh, E. Kjeang, G. G. Wang, and R. K. N. D. Rajapakse, J. Power Sources, 274, 1208 (2015).

14. P. Millet, R. Ngameni, S. A. Grigoriev, and V. N. Fateev, Int. J. Hydrogen Energy, 36, 4156 (2011)

15. J. Wu et al., J. Power Sources, 184, 104 (2008)

16. R. Borup et al., Chem. Rev., 107, 3904 (2007).

17. P. Millet et al., Int. J. Hydrogen Energy, 36, 4134 (2011).

18. A. Ursua, L. M. Gandia, and P. Sanchis, Proc. IEEE, 100, 410 (2012).

19. V. Mehta and J. S. Cooper, J. Power Sources, 114, 32 (2003).

20. R. Ferrigno, A. D. Stroock, T. D. Clark, M. Mayer, and G. M. Whitesides, J. Am. Chem. Soc., 124, 12930 (2002).

21. E. R. Choban, P. Waszczuk, and P. J. A. Kenis, Electrochem. Solid-State Lett., 8 , A348 (2005).

22. E. Kjeang, R. Michel, D. A. Harrington, N. Djilali, and D. Sinton, J. Am. Chem. Soc., 130, 4000 (2008).

23. S. A. Mousavi Shaegh, N.-T. Nguyen, and S. H. Chan, Int. J. Hydrogen Energy, 36, 5675 (2011).

24. M.-A. Goulet and E. Kjeang, J. Power Sources, 260, 186 (2014).

25. A. Z. Weber et al., J. Appl. Electrochem., 41, 1137 (2011).

26. W. A. Braff, M. Z. Bazant, and C. R. Buie, Nat. Commun., 4, 2346 (2013).

27. N. Arroyo-Curras, J. W. Hall, J. E. Dick, R. A. Jones, and A. J. Bard, J. Electrochem. Soc., 162, A378 (2015).

28. S. M. Hosseini Hashemi, M. A. Modestino, and D. Psaltis, Energy Environ. Sci., 8, 2003 (2015).

29. R. E. Sioda, Electrochim. Acta, 15, 783 (1970).

30. R. E. Sioda, Electrochim. Acta, 16, 1569 (1971).

31. R. E. Sioda, J. Electroanal. Chem., 34, 399 (1972).

32. R. E. Sioda, Electrochim. Acta, 22, 439 (1977).

33. M. I. Gillespie, F. van der Merwe, and R. J. Kriek, J. Power Sources, 293, 228 (2015).

34. J. L. Hartvigsen, J. D. Smith, and F. Dogan, ECS Trans., 68, 133 (2015).

35. R. Alkire and B. Gracon, J. Electrochem. Soc., 122, 1594 (1975).

36. C. A. Rodriguez, M. A. Modestino, D. Psaltis, and C. Moser, Energy Environ. Sci., 7, 3828 (2014).

37. T. Reier, M. Oezaslan, and P. Strasser, ACS Catal., 2, 1765 (2012).

38. H. E. Darling, J. Chem. Eng. Data, 9, 421 (1964).

39. H. Bouazaze, S. Cattarin, F. Huet, M. Musiani, and R. P. Nogueira, J. Electroanal. Chem., 597, 60 (2006)

40. C. C. L. McCrory et al., J. Am. Chem. Soc., 137, 4347 (2015).

41. Y. Zheng et al., Nat. Commun., 5, 3783 (2014).

42. J. Jin et al., Energy Environ. Sci., 7, 3371 (2014)

43. A. Arora, J. C. T. Eijkel, W. E. Morf, and A. Manz, Anal. Chem., 73, 3282 (2001).

44. G. Korotcenkov, S. Do Han, and J. R. Stetter, Chem. Rev., 109, 1402 (2009).

45. T. Hübert, L. Boon-Brett, G. Black, and U. Banach, Sensors Actuators, B Chem., 157, 329 (2011)

46. S. K. Arya, S. Krishnan, H. Silva, S. Jean, and S. Bhansali, Analyst, 137, 2743 (2012)

47. M. Ganzhorn et al., ACS Nano, 5, 1670 (2011).

48. M. J. Anderson and R. M. Crooks, Anal. Chem., 86, 9962 (2014).

49. S. T. Thoroddsen, T. G. Etoh, and K. Takehara, Phys. Fluids, 19, 042101 (2007).

50. D. Fernandez, P. Maurer, M. Martine, J. M. D. Coey, and M. E. Mobius, Langmuir, 30, 13065 (2014).

51. X. Yang, F. Karnbach, M. Uhlemann, S. Odenbach, and K. Eckert, Langmuir, 31, 8184 (2015). 